Article

\title{
Optical Properties of Buffers and Cell Culture Media for Optofluidic and Sensing Applications
}

\author{
Van Thuy Hoang 1,2, Grzegorz Stępniewski 1,2, Karolina H. Czarnecka ${ }^{3,4}{ }^{\infty}$, Rafał Kasztelanic 1,2, \\ Van Cao Long ${ }^{5}$, Khoa Dinh Xuan ${ }^{6}$, Liyang Shao ${ }^{7}$, Mateusz Śmietana ${ }^{3,7, *(1)}$ and \\ Ryszard Buczyński ${ }^{1,2, *(1)}$ \\ 1 Faculty of Physics, University of Warsaw, Pasteura 7, 02-093 Warsaw, Poland; \\ Van-Thuy.Hoang@fuw.edu.pl (V.T.H.); grzegorz.stepniewski@itme.edu.pl (G.S.); \\ rafal.kasztelenic@fuw.edu.pl (R.K.) \\ 2 Institute of Electronic Materials Technology, Wólczyńska 133, 01-919 Warsaw, Poland \\ 3 Institute of Microelectronics and Optoelectronics, Warsaw University of Technology, Koszykowa 75, \\ 00-662 Warsaw, Poland; karolina.czarnecka@umed.lodz.pl \\ 4 Department of Biomedicine and Genetics, Medical University of Lodz, Pomorska 251, 92-213 Lodz, Poland \\ 5 Institute of Physics, University of Zielona Gora, Prof. Szafrana 4a, 65-516 Zielona Góra, Poland; \\ V.CaoLong@if.uz.zgora.pl \\ 6 Department of Physics, Vinh University, Le Duan 182, Vinh, Nghe An 420000, Vietnam; \\ khoadx@vinhuni.edu.vn \\ 7 Department of Electrical and Electronic Engineering, Southern University of Science and Technology, \\ Shenzhen 518055, China; shaoly@sustc.edu.cn \\ * Correspondence: msmietan@elka.pw.edu.pl (M.Ś.); ryszard.buczynski@fuw.edu.pl (R.B.)
}

Received: 28 December 2018; Accepted: 12 March 2019; Published: 18 March 2019

\begin{abstract}
Interactions between light and various cells in cultures, such as bacteria or mammalian cells, are widely applied for optical sensors and optofluidic systems. These microorganisms need to be kept in proper aqueous media, referred to as buffers or cell culture media, that are required, respectively, for stable storage or delivering biochemical nutrients for their growth. When experiments or numerical analyses on optical devices are performed, the properties of these media are usually considered to be similar to those of pure water, with negligible influence of biochemical compounds on the medium's optical properties. In this work, we investigated the transmission, material dispersion, and scattering properties of selected and widely used buffers and cell culture media. We show that the optical properties of these media may significantly vary from those of water. Well-defined properties of buffers and cell culture media are essential for proper design of various optical sensing or future optofluidic systems dealing with biological structures.
\end{abstract}

Keywords: optical properties; cell culture media; optofluidics; optical sensing; label-free biosensing

\section{Introduction}

Conducting research on microorganisms and cell cultures requires aqueous media that support their life functions. These media are often called buffers or cell culture media (CCM) when storage and growth are considered, respectively. While buffers are typically multicompound electrolytes, CCM are additionally enriched with nutrients, growth factors, hormones, and other biologically active substances required for in vitro growth, storage, or propagation of living cells. The ingredients of CCM have to mimic the composition of the nutrients, vitamins, minerals, and growth stimuli present in the natural environment of the microorganisms and tissue or the extracellular fluid in the case of cell cultures [1-3]. 
Three phases in the cell culture growth process can be distinguished, namely: the lag phase, when little or no increase in cell number is observed; the logarithmic growth phase, when the cell number increases exponentially; and the stationary phase, also called the plateau phase, when the number of cells remains constant. Cells are able to grow and divide in the CCM when it has a suitable composition, stable $\mathrm{pH}$ and nutrients, as well as the appropriate gas atmosphere $\left(\mathrm{CO}_{2}, \mathrm{O}_{2}\right)$. Cell growth is limited mainly by the availability of nutrients and overcompaction of the culture, leading to a decrease in the number of living cells (death phase) [2,3]. For optimizing the CCM properties corresponding to cell growth and survival, other factors, including temperature, humidity, stability of buffer components, and specific illumination, are also of high importance [1,2]. Bacterial or fungal infection of CCM can lead to death of cultivated cells. Thus, to grow cells in CCM, it is necessary to respect the principles of sterile work-in laboratory practice, all manipulations are performed in laminar flow chamber in clean rooms. Moreover, to maintain the cell culture, regular check-ups and medium replacements are performed.

Knowledge of interactions between light and various cultured organisms is essential for therapeutic [4] or detection [5] purposes. The most common optical methods are used to monitor cell growth condition and are based on densitometry evaluation [3]. Optical density measurements of a small volume of cultured cells suspended in culture medium, usually at $\lambda=600 \mathrm{~nm}$ (OD600), are made in order to determine the growth kinetics, especially the determination of entering the plateau phase. This method can also be used for establishing conditions when the cells reproduce the fastest or show the expected morphological changes $[3,6]$. When the cultured cells change their morphological or cytological properties, or when they stop growing, the biochemical composition of the medium may also exhibit detectable differences. In most the cases, factors such as microbiological infection, use of inadequate media (lack of growth factors or other stimulants), presence of chemical contamination, or improper growth conditions (temperature, humidity, $\mathrm{CO}_{2}$ atmosphere) are considered to be responsible for disturbing cell life functions. For this reason, some media contain a $\mathrm{pH}$-dependent dye, changing their color when they become older, they accumulate cell metabolites, or there are products of nutrient degradation. This effect seems to be important mainly in colorimetric and spectrophotometric analyses, especially when the color of the used media disturbs the measurement [2-4]. For the majority of living cells, monitoring is performed in the visible and near-infrared spectral range $(\lambda=390-700 \mathrm{~nm})$ to reduce the energy supplied to the cells and to maintain the properties of the dyes used in the analysis. Real-time analysis of tissues (millimeters to centimeters in depth) is carried on, in turn, in the near-infrared range $(\lambda=650-900 \mathrm{~nm})$ to distinguish the absorption peaks corresponding to the absorption of blood or water $[7,8]$. However, changes in the optical properties of the used buffers or CCM, apart from the color or turbidity changes, are typically not investigated, since they may not be crucial for achieving the research aim, which is usually cell growth with no microbiological and mycological infection.

Several optical fiber sensors have been reported for microorganism monitoring [9]. These sensors mainly rely on a label-free sensing mechanism, where changes in optical properties or the thickness of the growing biological films are monitored in the vicinity of the sensor surface [10-13]. For these devices, the influence of the optical properties of the applied buffers or CCM is important to identify sensitivity and the limit of detection, but it is usually neglected. For measurements and numerical analyses, the optical properties of these liquids are considered to be equivalent to those of water, which may have a negative impact on the performance of these devices and the interpretation of data obtained during measurements.

There is also a number of fluorescence-based systems where CCM are applied and a change in their properties is crucial for the system's performance. The photonic explorer for bioanalysis with biologically localized embedding (PEBBLE) is considered to be one of the most developed methods of the real-time imaging of living cells $[8,14]$. In this method, the response comes from the fluorescent dye incorporated into the analyzed cell. The fluorescence intensity is not only dependent on the fluorescence quantum yield of the dye and the excitation source but also on absorbance (i.e., optical path length, solute concentration, and molar extinction coefficient) [15]. The detected fluorescent 
signal originates from in-vitro-cultivated cells and can be partially absorbed or scattered by other cells. The optofluidic resonator rings laser, where riboflavin dissolves in water has been considered an active medium, should also be mentioned here [16]. Use of fluorescent proteins as a viable gain medium for optical amplification has been demonstrated $[17,18]$. In this type of optofluidic application, proteins as well as bacteria and cells genetically modified with a fluorescent label need to stay in buffer or CCM. However, the putative impact of the optical properties of the medium is usually omitted for aqueous solutions. The fluorescent emission peak of the analyzed fluorescent probe can be strongly shifted due to the environment (i.e., polarity of the solute) [15]. For these purposes, the study of the optical properties of such media, which include scattering and material dispersion, are also highly demanded.

In this study, we examined for the first time the optical properties of a set of solutions commonly used as buffers and CCM. We determined their optical transmission range, scattering properties, and refractive indices. As a reference, pure water was used for comparison with the obtained results. The influence of the long-term handling of these liquids on the investigated properties is also discussed based on the preliminary experimental results.

\section{Materials and Methods}

\subsection{Buffers and CCM}

The liquids investigated in this experiment are commonly used in a wide range of cell culture procedures. Buffers are aqueous solutions consisting of a mixture of weak acid and a salt of this acid with a strong base, or a mixture of a weak base and a salt of this base with a strong acid. The investigated buffers are widely used in molecular biology, such as in electrophoresis, Western blots, cell suspensions, and procedures requiring DNA or RNA suspension. For the purpose of this study, we selected two widely used buffers, namely, Dulbecco Phosphate Buffered Saline (PBS) and TRIS-Borate-EDTA Buffer (TBE). TBE contains TRIS (tris(hydroxymethyl)aminomethane), boric acid, and ethylenediaminetetraacetic acid (EDTA), where EDTA is responsible for chelating divalent cations such as $\mathrm{Mg}^{2+}$ in the solutions. In many biological procedures, TBE is issued to stabilize nucleic acids against enzymatic degradation [19]. PBS, in turn, contains $\mathrm{NaCl}$, a phosphate buffer, and $\mathrm{KCl}$. It has a $\mathrm{pH}$ of 7, which is neutral and allows for cell survival and performing analyses with RNA and proteins. These buffers do not contain any coloring ingredients/components.

The two selected CCM, namely, Express Five ${ }^{\mathrm{TM}}$ SFM (EXPRESS 5) and Dulbecco's Modified Eagle's Medium (DMEM), are widely used in many types of human and mammalian cell cultures or procedures, where protein products need to be overexpressed for further analysis $[1-3,5,6]$. The CCM have to contain specific nutrients such as glucose, sodium pyruvate (source of energy), specific egzogenous amino acids, $\mathrm{NaHCO}_{3}$, and buffering salts [2]. They usually also have colored ingredients and specific $\mathrm{pH}$-dependent dyes for visual monitoring of any adverse $\mathrm{pH}$ change [2,3]. The investigated CCM contained a phenol red dye-Phenolsulfonphthalein. This dye can gradually transition from yellow in a pH of $6.2\left(\lambda_{\max }=443 \mathrm{~nm}\right)$ up to red in a pH of $8.2\left(\lambda_{\max }=570 \mathrm{~nm}\right)$; in a more alkaline $\mathrm{pH}(\mathrm{pH}>8.2)$, phenol red becomes bright pink. While using the CCM, the color change can indicate the loss of medium stability or change in composition. This may take place when the cultured cells excrete to the solution their metabolites, causing a change of $\mathrm{pH}$. In cell culture practice, the color change may give information regarding whether or not the medium still contains the nutrients or other required substances, such as vitamins and growth factors, or if there has been over compaction of the culture [1,2]. The main properties of the liquids considered in this work are summarized in Table 1.

The buffers and CCM used in the study after first use were stored in a fridge for the entire analysis period (up to 8 months). Containers with the buffers and CCM were tempered for at least $30 \mathrm{~min}$ at room temperature prior to measurements. Fast heating up was avoided in order to maintain the CCM properties, as $\mathrm{CCM}$ contains carbonate ions (from $\mathrm{NaHCO}_{3}$ ) and fast heating could slightly change the $\mathrm{pH}$ to more alkaline. The measurements were performed for buffers and CCM as typically used, that is, without added reagents such as, for example, serum (e.g., fetal bovine serum), L-glutamine 
(in the case of High Five), or antibiotics (e.g., gentamycin). The use of the aforementioned additives depends on the type of cultivating cells and the planned analysis and vary considerably based on the cell culture protocol used. Measurements were performed without external change of the $\mathrm{pH}$. Most of the CCM used for mammalian cell cultures have a $\mathrm{pH}$ of $\sim 7.4$ - the value is optimized for different cell types. Some cell types grow better in slightly different pHs (e.g., skin fibroblasts at 7.4-7.7, or some cancer cell lines at 7.0-7.4). An acidic $\mathrm{pH}$ can mimic the environment in the tissue surrounding the cancer lesion, as cancer cells have a much higher metabolic rate and expel many more protons through membrane-based mechanisms in order to regulate intracellular $\mathrm{pH}$.

Table 1. The main properties of the investigated buffers and cell culture media (CCM).

\begin{tabular}{|c|c|c|c|c|}
\hline & $\begin{array}{l}\text { Stability } \\
\text { (months) }\end{array}$ & $\begin{array}{c}\text { Storage } \\
\text { Temperature }\left({ }^{\circ} \mathrm{C}\right)\end{array}$ & Composition & $\begin{array}{l}\text { Producer, Formal } \\
\text { Characteristics }\end{array}$ \\
\hline $\begin{array}{c}\text { TBE } \\
\text { (TRIS-Borate-EDTA } \\
\text { Buffer) }\end{array}$ & 24 & $15-30$ & $\begin{array}{c}89 \mathrm{mM} \text { Tris, } 89 \mathrm{mM} \text { boric } \\
\text { acid, } 2 \mathrm{mM} \text { EDTA; } \mathrm{pH} \\
\sim 8.3 \text { at } 25^{\circ} \mathrm{C}\end{array}$ & $\begin{array}{c}\text { Buffer, } \\
\text { Merck-Millipore cat. } \\
\text { No. } 574795\end{array}$ \\
\hline $\begin{array}{c}\text { PBS } \\
\text { (HyClone }^{\mathrm{TM}} \text { Dulbecco's } \\
\text { Phosphate Buffered } \\
\text { Saline solution) }\end{array}$ & 24 & $15-30$ & $\begin{array}{c}140 \mathrm{mM} \mathrm{NaCl}, 10 \mathrm{mM} \\
\text { phosphate buffer, } 3 \mathrm{mM} \\
\mathrm{KCl} \text {; } \mathrm{pH} 7.4 \text { at } 25^{\circ} \mathrm{C}\end{array}$ & $\begin{array}{c}\text { Buffer, GE } \\
\text { Healthcare cat. No. } \\
\text { SH30028.02 Hyclone }\end{array}$ \\
\hline $\begin{array}{c}\text { EXPRESS } 5 \\
\text { (Cell culture medium } \\
\text { Express Five }^{\mathrm{TM}} \text { SFM) }\end{array}$ & 18 & $2-8$ & $\begin{array}{l}\text { sodium pyruvate } \\
\mathrm{NaHCO}_{3} \text {, low glucose, } \\
\text { low phenol red; } \\
\text { serum-free medium }\end{array}$ & $\begin{array}{l}\text { Used for protein } \\
\text { purification and in } \\
\text { Baculovirus } \\
\text { Expression Vector } \\
\text { System; Gibco cat. } \\
\text { No. 10486-025 }\end{array}$ \\
\hline $\begin{array}{c}\text { DMEM } \\
\text { (Cell culture medium } \\
\text { Dulbecco's Modified } \\
\text { Eagle's Medium) }\end{array}$ & 6 & $2-8$ & $\begin{array}{l}\text { sodium pyruvate, } \\
\mathrm{NaHCO}_{3} \text {, low glucose, } \\
\text { phenol red. }\end{array}$ & $\begin{array}{l}\text { Used for cell culture; } \\
\text { SIGMA cat. No. } \\
\text { D5796 }\end{array}$ \\
\hline
\end{tabular}

\subsection{Optical Analysis}

The transmission properties of the liquids in the spectral range of 400-1600 nm were investigated using a standard high-quality fused silica cuvette with a square cross section $(10 \times 10 \mathrm{~mm}$ and $100-\mu \mathrm{m}$-thick walls). The influence of the cuvette on the obtained results in the specified range was negligible. As a light source, a fiber-coupled HL-2000 halogen lamp (Ocean Optics Inc., Largo, FL, USA) was used to ensure a stable and flat input spectrum. The light was collimated by an achromatic microscope objective $\mathrm{L} \times 20$. Next, and the transmission was measured with two (visible and infrared) spectrometers (Red Tide, Ocean Optics Inc., Largo, FL, USA and AvaSpec-NIR256/512-1.7, Avantes BV, Apeldoorn, The Netherlands). The output beam after the cuvette was split into two parts by flip mirror $M$ to ensure robust coupling conditions into both spectrometers. The experimental setup used for transmission measurements is shown in Figure 1a.

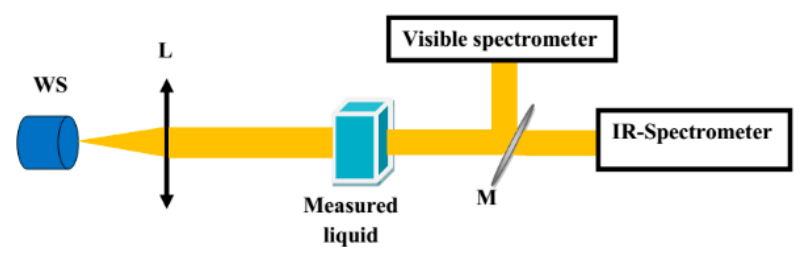

(a)

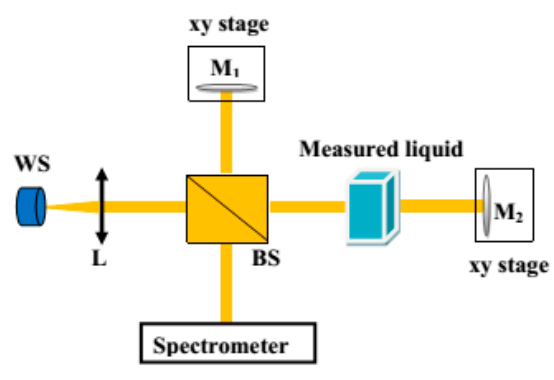

(b)

Figure 1. Scheme of the setup used for measuring (a) transmission and (b) material dispersion of the liquids. 
Group refractive index $N$ was measured by the white light interferometric technique and phase refractive index $n$ was measured with an Abbe refractometer (RL-3, PZO S.A. Warsaw, Poland) while $n_{D}$ was defined at $\lambda=589 \mathrm{~nm}$ [11]. A Michelson interferometer setup was used for measurement $N$ of the liquids (Figure 1b). In this setup, the cuvette was placed in the signal arm of the interferometer. The reference arm was equipped with a mirror $M_{1}$ mounted on a translation stage, which enabled compensation and measurement of the optical path difference (OPD) introduced by the bio-liquid in the signal arm. The interference patterns were observed and analyzed with the spectrometers in the visible and near-infrared spectral range. Measurement of the OPD as a function of the equalization wavelength allowed for determination of the spectral dependence of $N$. The obtained curve could be fitted by the function describing $N(\lambda)$ by including Sellmeier coefficients, as in Equation (1), where the phase refractive index $n(\lambda)$ is given by the Sellmeier formula, as in Equation (2), where, in turn, $\mathrm{n}$ is the refractive index, $\lambda$ is the wavelength, and $B_{1,2,3}$ and $C_{1,2,3}$ are Sellmeier coefficients:

$$
\begin{gathered}
N(\lambda)=n(\lambda)+\frac{\lambda^{2}}{n(\lambda)} \sum_{i=1}^{3} \frac{B_{i} C_{i}}{\left(\lambda^{2}-C_{i}^{2}\right)} \\
n=\sqrt{1+\frac{B_{1} \lambda^{2}}{\lambda^{2}-C_{1}}+\frac{B_{2} \lambda^{2}}{\lambda^{2}-C_{2}}+\frac{B_{3} \lambda^{2}}{\lambda^{2}-C_{3}}}
\end{gathered}
$$

To verify the homogeneity and scattering properties of the liquids, we measured their angular characteristics of scattered light. As a light source, we used a single-mode semiconductor laser (LP660-SF60, Thorlabs Inc., Newton, NJ, USA) operating at $\lambda=658 \mathrm{~nm}$. The collimated light beam from the source was directed to the Aperture 1, having a diameter of $0.3 \mathrm{~mm}$, and further to the cuvette with the liquids. Here, a cylindrical glass cuvette was used to minimize the influence of the container on the direction of light propagation. The diameter of the cuvette was $130 \mathrm{~mm}$. The detecting part of the setup was placed on a rotation stage that allowed collection of scattered signals in the angular range $-90^{\circ}$ to $90^{\circ}$. This part of the setup included Aperture $2(1.5 \mathrm{~mm}$ diameter), lens $L$, and a power meter (Figure 2).

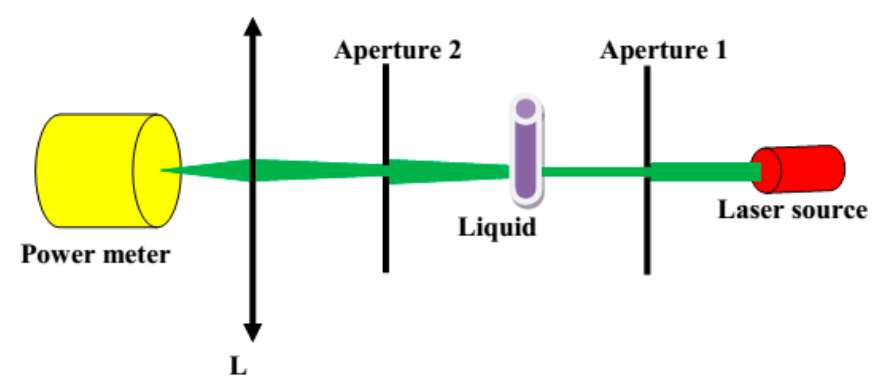

Figure 2. Scheme of the setup used for measuring scattering properties.

\section{Results and Discussion}

Transmission spectra for all the considered liquids are presented in Figure 3. In general, transmission of all the liquids was limited by the transmission spectrum of water, which is the main ingredient of all of them. The IR part of the spectra $(\lambda>700 \mathrm{~nm})$ followed typical water transmission characteristics with two absorption peaks at 950 and $1200 \mathrm{~nm}$ and almost no transmission at $1400 \mathrm{~nm}$. Transmission spectra of TBE and PBS were similar to that of water in the visible range as well. Simple salts (TRIS, boric acid, EDTA, $\mathrm{NaCl}$, phosphate buffer, and $\mathrm{KCl}$ ) added to water did not change its absorption in the visible spectral range. However, compared with buffers, the transmission of CCM was significantly different. EXPRESS 5 showed a significantly reduced transition below $600 \mathrm{~nm}$, which is related to the absorption of nutrients (e.g., glucose, sodium pyruvate). The DMEM transmission characteristics had, in turn, a very broad and deep absorption peak with a maximum at $560 \mathrm{~nm}$. 
This peak was caused by a high concentration of phenol red dye-phenolsulfonphthalein absorption in $\mathrm{pH} 8.2\left(\lambda_{\max }=570 \mathrm{~nm}\right)$.

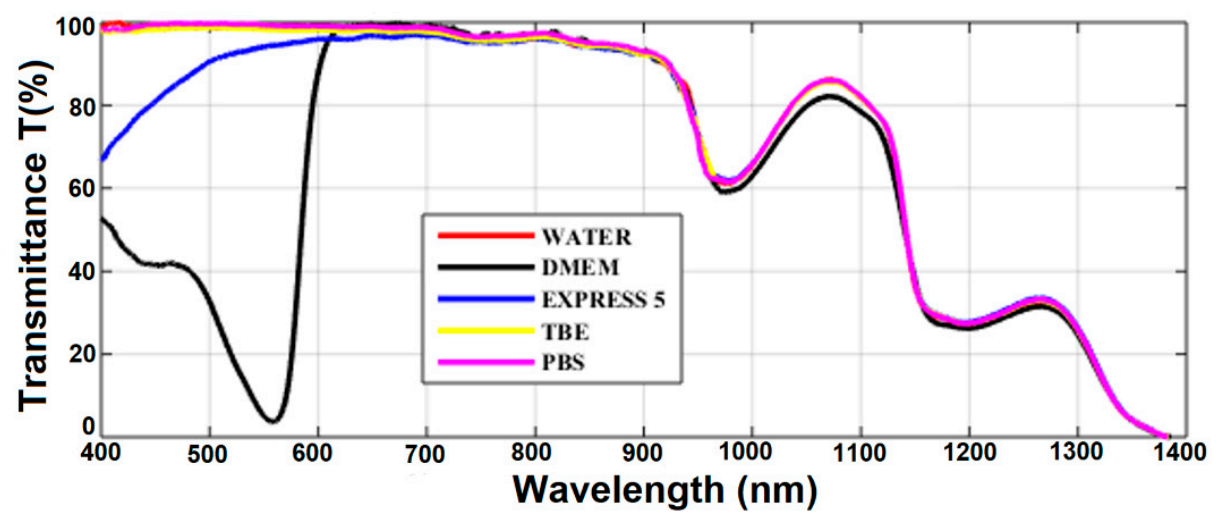

Figure 3. The transmission of the investigated liquids measured in the 10-mm-long cuvette. Results for pure water are provided for reference. Legend: TBE-TRIS-Borate-EDTA Buffer; PBS-Dulbecco's Phosphate Buffered Saline solution; EXPRESS 5-Cell culture medium Express Five ${ }^{\mathrm{TM}}$ SFM; DMEM—Cell culture medium Dulbecco's Modified Eagle's Medium.

To verify the influence of long-term handling on buffers and CCM, we also measured their transmission after 3 and 8 months (Figure 4). During 8-month-long storage, all the media were kept in the dark and at a temperature of $4{ }^{\circ} \mathrm{C}$. For the TBE buffer (Figure 4c), we did not observe any change in transmission. This buffer was stable during the 8-month-long storage. High stability is related to the composition of TBE, which contains TRIS, boric acid, and EDTA, offering slightly alkaline $\mathrm{pH}$ conditions. Moreover, the presence of EDTA is very important due to its chelator activity, particularly for magnesium ions $\left(\mathrm{Mg}^{2+}\right)$. These ions act as cofactors and are required for the activation of many enzymes; therefore, the absence of $\mathrm{Mg}^{2+}$ may block bacteria growth. In the case of PBS, we observed a gradual reduction of the transmission peak centered at $1100 \mathrm{~nm}$ (Figure $4 \mathrm{~d}$ ). The visible part of the spectrum remained unchanged after the first 3 months, and later between the third and eighth months, we noticed a reduction in transmission from $10 \%$ to $25 \%$ at $\lambda=600 \mathrm{~nm}$ and $\lambda=400 \mathrm{~nm}$, respectively. This effect was possibly induced by the crystallization of salts in the buffer. However, in comparison with the CCM, the process was less intense.

For CCM, we observed a well-visible reduction of transmission properties for both of the liquids. Their transmission properties remained comparable for the first 3 months, but between the third and eighth months, an intensive decrease of transmission was observed. For EXPRESS 5, this effect was related to strong light scattering caused by medium degradation and/or by bacterial or fungi infection. $\mathrm{CCM}$ are usually used for no longer that 1 month from the date of first use and it is recommended by the manufacturer to use them within 2-4 weeks. Moreover, CCM should be used in a clean-room environment and a chamber with laminar flow to reduce the likelihood of infection. Every use of the medium increases the probability of bacterial or fungi infection. The observed effect may have been caused by nutrient degradation due to the half-life of the molecules or the fact that the media were measured at normal atmosphere (with a low $\mathrm{CO}_{2}$ concentration, $\sim 0.4 \%$ ). In cell cultures, the $\mathrm{CO}_{2}$ concentration in the incubator is at a much higher level (usually $5 \%$ or $10 \%$ ), and the $\mathrm{CO}_{2}$ dissolved in the medium is converted into $\mathrm{H}^{+}$and $\mathrm{HCO}_{3}{ }^{-}$ions, which helps to stabilize the $\mathrm{pH}$. CCM that are not kept in an atmosphere with a high $\mathrm{CO}_{2}$ concentration show limited $\mathrm{pH}$ buffering properties and are more likely to degrade.

Group and phase refractive indices of water and the other investigated liquids were calculated according to Equation (1) and using interferograms, as shown in Figure 5. The obtained material dispersion of water was similar to that previously reported by Chen et al. [11], which confirms the correctness of our experimental results. The calculated Sellmeier coefficients are given in Table 2. 

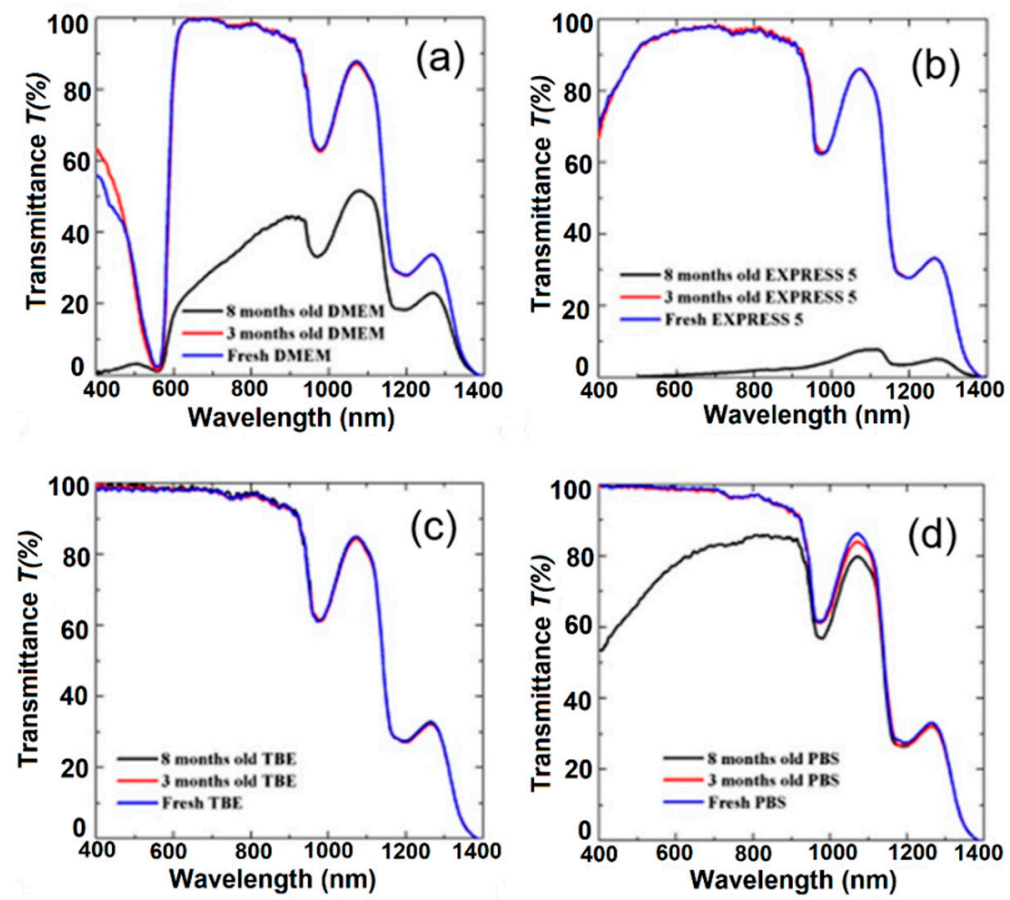

Figure 4. The effect of long-term handling on transmission characteristics of (a) DMEM, (b) EXPRESS 5, (c) TBE, and (d) PBS. Legend: TBE-TRIS-Borate-EDTA Buffer; PBS-Dulbecco's Phosphate Buffered Saline solution; EXPRESS 5-Cell culture medium Express Five ${ }^{\mathrm{TM}}$ SFM; DMEM-Cell culture medium Dulbecco's Modified Eagle's Medium.
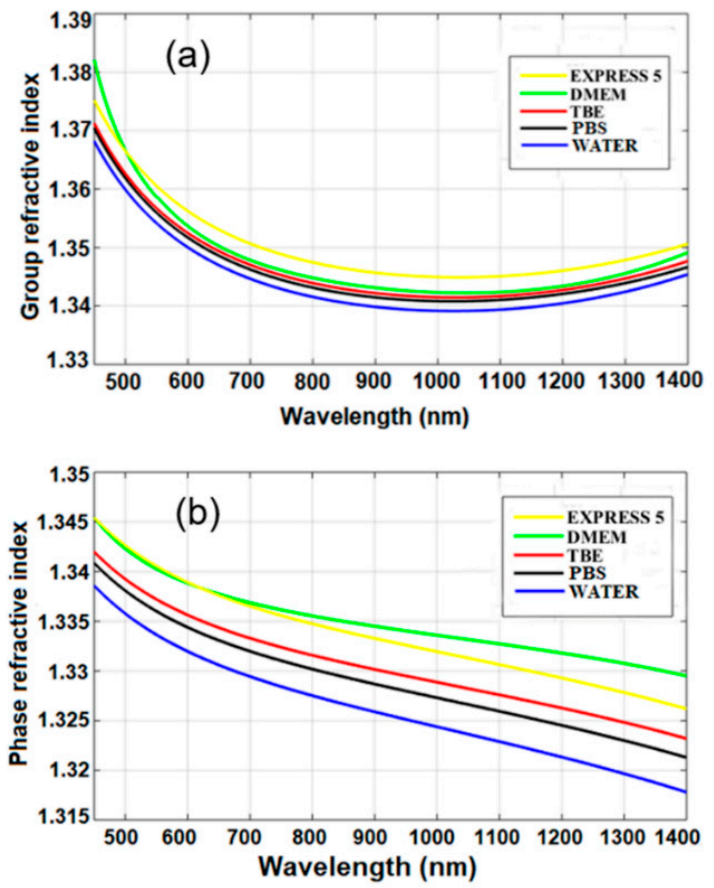

Figure 5. (a) Group and (b) phase refractive indices measured for the investigated liquids. Legend: TBE-TRIS-Borate-EDTA Buffer; PBS—Dulbecco's Phosphate Buffered Saline solution; EXPRESS 5-Cell culture medium Express Five ${ }^{\mathrm{TM}}$ SFM; DMEM-Cell culture medium Dulbecco's Modified Eagle's Medium. 
Table 2. Sellmeier coefficients of the investigated liquids. Legend: TBE-TRIS-Borate-EDTA Buffer; PBS-Dulbecco's Phosphate Buffered Saline solution; EXPRESS 5-Cell culture medium Express Five ${ }^{\mathrm{TM}}$ SFM; DMEM-Cell culture medium Dulbecco's Modified Eagle's Medium.

\begin{tabular}{ccccc}
\hline & DMEM & EXPRESS 5 & TBE & PBS \\
\hline$B_{1}$ & 0.770818 & 0.775107 & 0.766475 & 0.763614 \\
$B_{2}$ & $-12,415.01$ & -8912.71 & -9070.89 & -9246.06 \\
$B_{3}$ & 73.6953 & 41.0681 & 40.3204 & 47.7781 \\
$C_{1}\left(\mu \mathrm{m}^{2}\right)$ & 0.00945 & 0.00907 & 0.00898 & 0.00905 \\
$C_{2}\left(\mu \mathrm{m}^{2}\right)$ & $22,578.45$ & $31,067.85$ & $30,520.46$ & $30,036.29$ \\
$C_{3}\left(\mu \mathrm{m}^{2}\right)$ & 135.0971 & 140.2136 & 133.3024 & 151.858 \\
\hline
\end{tabular}

Based on the obtained results, we can conclude that $n$ in the near-infrared range of the CCM and buffers was higher than that of water by up to $\Delta n=0.012$. The higher $n$ was induced by added chemical and biochemical nutrients. The $n$ of buffers was, on average, higher only by $0.08 \%$ than that of water. The $n$ of CCM was, on average, higher by $0.2 \%$ than that of water, and the difference corresponds to the added biochemical nutrients which increase their $n$. In the case of standard biological applications, these differences can be negligible. However, they should be taken into account when using those media for label-free biosensing devices.

The influence of long-term handling on the $n_{D}$ was investigated next and the obtained results are shown in Table 3. No significant changes for any of the considered media were observed. An increase of $n_{D}$ for 8-months-stored PBS was probably a result of salt crystallization. This measurement supported data obtained in the case of transmission measurements, where the same sample behaved differently.

Table 3. Evolution of investigated liquids' refractive index $\left(n_{D}\right)$ with storage time. Legend: TBE-TRIS-Borate-EDTA Buffer; PBS—Dulbecco's Phosphate Buffered Saline solution; EXPRESS 5-Cell culture medium Express Five ${ }^{\mathrm{TM}}$ SFM; DMEM-Cell culture medium Dulbecco's Modified Eagle's Medium.

\begin{tabular}{cccc}
\hline & Fresh & 3 Months & 8 Months \\
\hline DMEM & 1.3370 & 1.3373 & 1.3375 \\
EXPRESS 5 & 1.3381 & 1.3381 & 1.3381 \\
TBE & 1.3360 & 1.3362 & 1.3362 \\
PBS & 1.3348 & 1.3349 & 1.3362 \\
\hline
\end{tabular}

Scattering losses in the investigated liquids were analyzed next. Normalized intensity $\mathrm{P} \alpha / \mathrm{P}_{0}$, defined as the ratio between the intensity measured at angle $\alpha$ and the intensity at angle $\alpha=0$, was used to show the scattering of culture cell media and buffers (Figure 6). Also, the scattering properties of water are shown here for reference. We observed that normalized intensity decreased exponentially with the angle. For an angle higher than $45^{\circ}$, scattering intensity dropped nearly to zero. The obtained characteristics of fresh samples were very similar to those of water. It seems that the biochemical nutrients present in the CCM do not induce any additional scattering with respect to that of water, mostly due to the fact that their size is much smaller than the wavelength of the laser source.

Similar experiments were repeated after 3 and 8 months (Figure 7). For DMEM, EXPRESS 5, and PBS, we observed a significant increase of scattering. Only in the case of TBE did scattering remain unchanged. These results agree with the measurements of the transmission of the liquids, where DMEM, EXPRESS 5, and PBS changed in time, while TBE remained unchanged. This behavior is related to the presence of substances enabling microorganism growth (such as nutrients and simple salts) in DMEM and EXPRESS 5, or salt crystallization in the case of PBS. Moreover, in CCM, after longer storage, the nutrients decomposed due to their limited half-life, causing media degradation. The stability of TBE was significantly higher due to the EDTA chelating properties and its slightly alkaline $\mathrm{pH}$. 


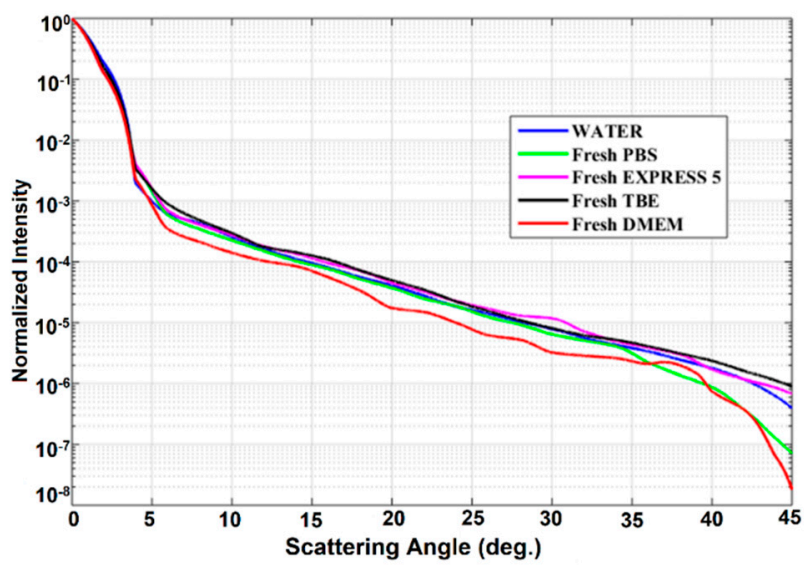

Figure 6. Scattering properties of the investigated liquids. Legend: TBE-TRIS-Borate-EDTA Buffer; PBS-Dulbecco's Phosphate Buffered Saline solution; EXPRESS 5-Cell culture medium Express Five ${ }^{\mathrm{TM}}$ SFM; DMEM-Cell culture medium Dulbecco's Modified Eagle's Medium.
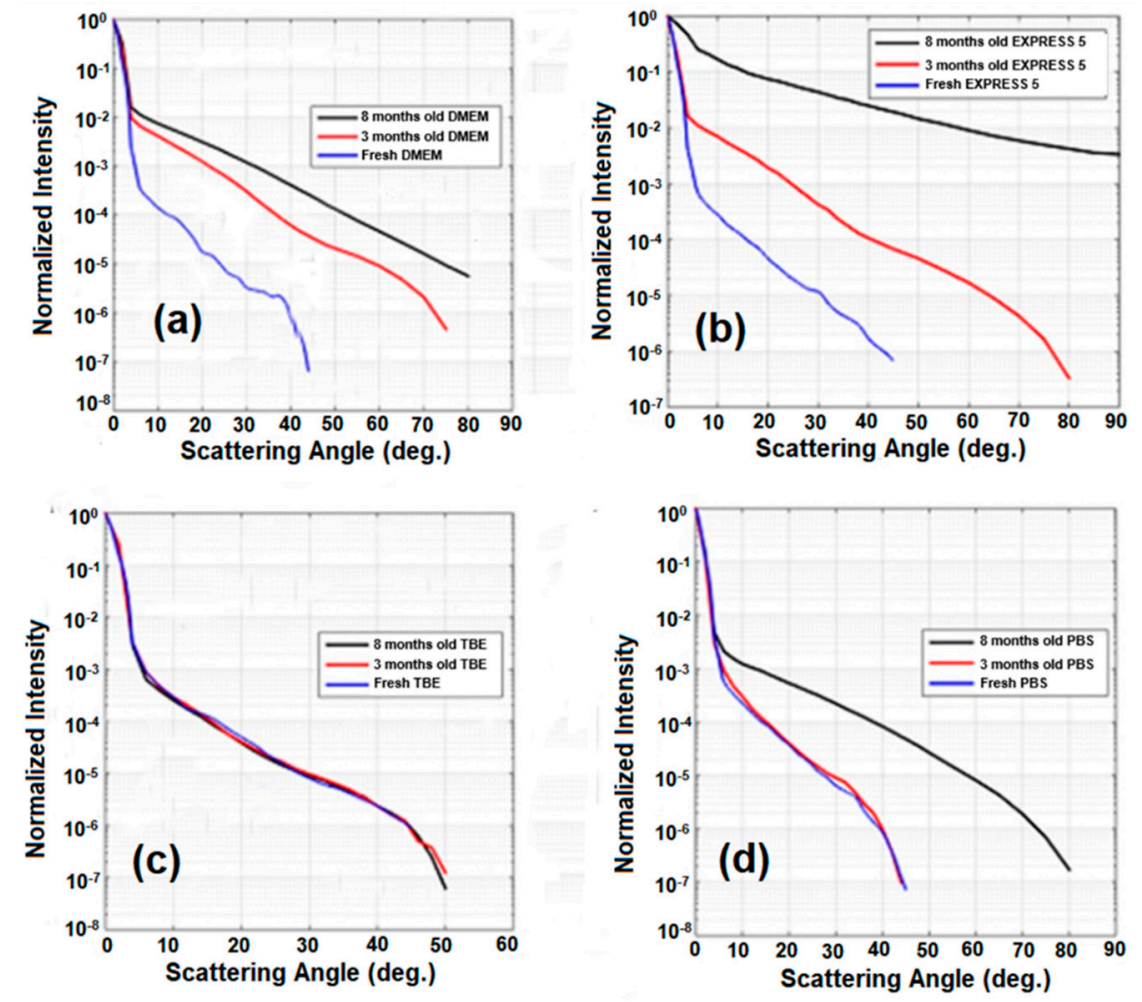

Figure 7. Light scattering characteristics after 3- and 8-months-long storage time for (a) DMEM, (b) EXPRESS 5, (c) TBE, and (d) PBS. Legend: TBE-TRIS-Borate-EDTA Buffer; PBS-Dulbecco's Phosphate Buffered Saline solution; EXPRESS 5-Cell culture medium Express Five ${ }^{\mathrm{TM}}$ SFM; DMEM-Cell culture medium Dulbecco's Modified Eagle's Medium.

\section{Conclusions}

We have measured the optical properties of selected commercially available buffers, such as PBS and TBE, as well as selected cell culture media-EXPRESS 5 and DMEM. These liquids are widely used in biomedical research for the growth and storage of live cells. In particular, we verified to what extent the optical properties of the liquids correspond to those of water, which are often assumed to be equivalent in numerical modeling. The transmission properties of buffers are comparable to those of water, but cell culture media show a significant reduction of transmission in a spectral range below $550 \mathrm{~nm}$. This property may strongly limit the application of these media in devices where 
florescence is measured (sensors) or used as a gain medium (optofluidic laser). Measurements of material dispersion, in turn, have shown that refractive indices of these liquids are significantly higher than that of water due to the presence of biochemical nutrients, as well as the weak acid and salt of this acid. The differences in the near-infrared range may reach up to 0.012 and 0.006 for culture media and buffers, respectively. They might be negligible for biological experiments, but when these liquids are used in label-free biosensors, the differences may be important and should be taken into account at the sensor-design stage. The measured properties are, in particular, important for the development of label-free optical biosensors as well as for optical active fiber systems, where fluorescent proteins or genetically modified bacteria are considered as a gain medium [16-18]. In the latter case, accurate knowledge of the optical properties of the media is required for the proper design of optical fibers with an active liquid core. In addition, we have also shown that scattering for the examined liquids in the visible spectral range is similar to that of water; therefore, only from this point of view water can be considered as equivalent in properties.

In general, buffers and CCM have good optical properties and can be used as optical medium for various biophotonic systems, including novel ones that employ various genetically modified cells, where the media are required to sustain cell living functions and growth. However, the long-term stability of these media must be also taken into account. We observed their significant change in properties after 8 months of storage. The changes concern CCM and PBS, where they may be originated by infection or degradation and salt crystallization, respectively. The change was only limited for the TBE buffer, which can be explained by the slightly alkaline $\mathrm{pH}$ and the presence of EDTA $\left(\mathrm{Mg}^{2+}\right.$ ion chelator) inactivating bacterial enzymes and blocking the multiplication of bacteria. For the majority of the investigated media, scattering increased with time. The main reason for those phenomena in the case of CCM was the degradation of the biological components of the liquids and the putative development of bacteria and/or fungi. The components enable not only the growth of cells of interest but also the rapid growth of bacteria, which may strongly influence the optical properties of the liquid. The probable source of microorganism infection may be inappropriate CCM handling, as the spectrophotometric analyses were performed out of the laminar or clean room-the same conditions as in many photonic labs. The significant change in optical properties during long-term handling can produce misleading results in optical measurements. Moreover, monitoring the optical parameters of the liquids, such as transmission or scattering, may be used to identify degradation or infection, especially when long-term experiments are considered.

Author Contributions: Concept of the research and methodology was provided by R.B. and M.Ś.; V.T.H., G.S., K.H.C., and R.K. measured the properties of the cell culture media; V.C.L., K.D.X., L.S., R.B., and M.S. conducted modeling and results analysis; L.S., R.B., and M.Ś. jointly supervised this work. The manuscript was written by V.T.H., K.H.C., L.S., M.Ś., and R.B. with contributions from the remaining co-authors.

Funding: This research was funded by the Foundation for Polish Science Team Programme from the funds of European Regional Development Fund under the Smart Growth Operational Programme, grant number TEAM TECH/2016-1/1; National Science Centre (NCN) in Poland, grant numbers 2014/13/B/ST7/01742 and 2016/21/B/ST7/02249; National Foundation for Science and Technology Development (NAFOSTED) grant number 103.03-2014.62; National Natural Science Foundation of China, grant number 61475128; SUSTech sabbatical visiting scholar grant from the Academy for Advanced Interdisciplinary Studies, Southern University of Science and Technology, China.

Conflicts of Interest: The authors declare no conflict of interests.

\section{References}

1. McAteer, J.; Davis, J.M. Basic cell culture and the maintenance of cell lines. In Basic Cell Culture; Oxford University Press: Oxford, UK, 2002.

2. Cartwrightand, T.; Shah, G.P. Culture Media. In Basic Cell Culture; Oxford University Press: Oxford, UK, 2002.

3. Macleod, K.G.; Langdon, S.P. Essential Techniques of Cancer Cell Culture. In Cancer Cell Culture: Methods and Protocols; Springer: Berlin, Germany, 2004. 
4. Lynnyk, A.; Lunova, M.; Jirsa, M.; Egorova, D.; Kulikov, A.; Kubinova, S.; Lunov, O.; Dejneka, A. Manipulating the mitochondria activity in human hepatic cell line Huh7 by low-power laser irradiation. Biomed. Opt. Express 2018, 9, 1283-1300. [CrossRef] [PubMed]

5. Iloki Assanga, S.B.; Gil-Salido, A.A.; Lewis Luján, L.M.; Rosas-Durazo, A.; Acosta-Silva, A.L.; Rivera-Castañeda, E.G.; Rubio-Pino, J.L. Cell growth curves for different cell lines and their relationship with biological activities. Int. J. Biotechnol. Mol. Biol. Res. 2013, 4, 60-70. [CrossRef]

6. Riess, T.; Dietrich, F.; Schmidt, K.V.; Kaiser, P.O.; Schwarz, H.; Schäferand, A.; Kempf, V.A. Analysis of a novel insect cell culture medium-based growth medium for Bartonellaspecies. Appl. Environ. Microbiol. 2008, 74, 5224-5227. [CrossRef] [PubMed]

7. Cheong, W.F.; Prahl, S.A.; Welch, A.J. A review of the optical properties of biological tissues. IEEE J. Quantum Electron. 1990, 26, 2166-2185. [CrossRef]

8. Koo Lee, Y.E.; Kopelman, R.; Smith, R. Nanoparticle PEBBLE sensors in live cells and in vivo. Annu. Rev. Anal. Chem. (Palo Alto Calif) 2009, 2, 57-76. [CrossRef] [PubMed]

9. Vo-Dinh, T.; Kasili, P. Fiber-optic nanosensors for single-cell monitoring. Anal. Bioanal. Chem. 2005, 382, 918-925. [CrossRef] [PubMed]

10. Shevchenko, Y.; Camci-Unal, G.; Cuttica, D.F.; Dokmeci, M.R.; Albert, J.; Khademhosseini, A. Surface plasmon resonance fiber sensor for real-time and label-free monitoring of cellular behavior. Biosens. Bioelectron. 2014, 15, 359-367. [CrossRef] [PubMed]

11. Chen, S.; Svedendahl, M.; Käll, M.; Gunnarsson, L.; Dmitriev, A. Ultrahigh sensitivity made simple: nanoplasmonic label-free biosensing with an extremely low limit-of-detection for bacterial and cancer diagnostics. Nanotechnology 2009, 20, 434015. [CrossRef] [PubMed]

12. Brzozowska, E.; Koba, M.; Śmietana, M.; Górska, S.; Janik, M.; Gamian, A.; Bock, W.J. Label-free gram-negative bacteria detection using bacteriophage-adhesine-coated long-period grating. Biomed. Opt. Express 2016, 7, 829-840. [CrossRef] [PubMed]

13. Shao, L.; Liu, Z.; Hu, J.; Gunawardena, D.; Tam, H.-Y. Optofluidics in Microstructured Optical Fibers. Micromachines 2018, 9, 145. [CrossRef] [PubMed]

14. Clark, H.A.; Hoyer, M.; Philbert, M.A.; Kopelman, R. Optical Nanosensors for Chemical Analysis inside Single Living Cells. 1. Fabrication, Characterization, and Methods for Intracellular Delivery of PEBBLE Sensors. Anal. Chem. 1999, 71, 4831-4836. [CrossRef] [PubMed]

15. Haugland, R.P. The Handbook A guide to Fluorescent Probes and Labelling Technology, 10th ed.; Invitrogen: Carlsbad, CA, USA, 2005.

16. Lee, W.; Kim, D.B.; Song, M.H.; Yoon, D.K. Optofluidic ring resonator laser with an edible liquid laser gain medium. Opt. Express 2017, 25, 14043-14048. [CrossRef] [PubMed]

17. Fan, X.; Yun, S.-H. Optofluidic Bio-Lasers: Concept and Applications. Nat. Methods 2014, 11, $141-147$. [CrossRef] [PubMed]

18. Gather, M.C.; Yun, S.H. Single-cell biological lasers. Nat. Photonics 2011, 5, 406-410. [CrossRef]

19. Brody, J.R.; Kern, S.E. History and principles of conductive media for standard DNA electrophoresis. Anal. Biochem. 2004, 333, 1-13. [CrossRef] [PubMed]

(C) 2019 by the authors. Licensee MDPI, Basel, Switzerland. This article is an open access article distributed under the terms and conditions of the Creative Commons Attribution (CC BY) license (http://creativecommons.org/licenses/by/4.0/). 